\title{
Permeability Tests and Multi-Factor Analysis of Sand-Based Cemented Backfill Five-Component Samples With Different Mix Ratios
}

\section{Nan Zhou}

China University of Mining \& Technology

\section{Yinan Yao}

China University of Mining \& Technology

Jixiong Zhang

China University of Mining \& Technology

Hao Yan

China University of Mining \& Technology

Cunli Zhu ( $\square$ cumtzhucunli@163.com )

China University of Mining \& Technology

\section{Meng Li}

China University of Mining \& Technology

\section{Research Article}

Keywords: Groundwater seepage, sand-based cemented backfill, permeability, sensitivity analysis, microstructure

Posted Date: October 12th, 2021

DOI: https://doi.org/10.21203/rs.3.rs-946747/v1

License: (9) This work is licensed under a Creative Commons Attribution 4.0 International License. Read Full License 
1 Permeability tests and multi-factor analysis of sand-based cemented

2 backfill five-component samples with different mix ratios

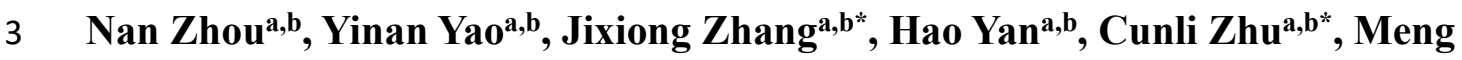

$4 \quad \mathbf{L i}^{\mathbf{a}, \mathbf{b}}$

$5 \quad{ }^{a}$ State Key Laboratory of Coal Resources and Safe Mining; China University of Mining \&

6 Technology, Xuzhou, Jiangsu 221116, China

${ }^{b}$ School of Mines, China University of Mining \& Technology, Xuzhou, Jiangsu 221116, China

8 Corresponding Author:

$9 \quad$ Jixiong Zhang; Tel: +86-18570489749; E-mail: 18570489749@163.com

Cunli Zhu; Tel: +86-13852036592; E-mail: cumtzhucunli@163.com

\section{Abstract:}

Extensive coal mining involves the challenge of liberating coal resources under buildings, railways, and water bodies. Sand-based cemented backfill (SCB) mining is considered an effective method to solve this problem while utilizing solid wastes in large quantities. Since the groundwater seeping into SCB pores in a complex mining environment deteriorates the SCB strength and stability, the permeability optimization of SCB samples under multi-factor conditions by adjusting their mix ratios is very topical. Therefore, in this study, a large number of SCB samples were prepared using aeolian sand as aggregates, cement and fly ash as cementing materials, and quicklime and water reducing agent as additives. The mass of the aeolian sand was a fixed value, while other ingredients' content ratios were expressed as a percentage of aeolian sand mass. With all other factors being constant, the level of one factor was changed at a time for univariate analysis. Four levels were set up for each of the four factors, and 16 tests were performed for a total of 13 mix ratios with an axial pressure of $1 \mathrm{MPa}$ and confining pressure of $3 \mathrm{MPa}$. The effects of mix ratios, pore size, porosity, and surface structure on SCB's permeability were analyzed in detail. Experimental results show variations of quicklime and fly ash contents significantly changed the SCB's permeability, and variations of cement and water reducing agent contents had a minor impact on SCB's permeability. SCB's permeability positively correlated with porosity, primary pore size, and compactness of surface structure. These findings are considered instrumental in improving the SCB waterproof performance. 
Keywords: Groundwater seepage; sand-based cemented backfill; permeability; sensitivity analysis; microstructure

\section{Declarations}

Funding: This work was supported by the National Natural Science Foundation [grant number 51874287].

Competing interests: The authors declare that they have no known competing financial interests or personal relationships that could have appeared to influence the work reported in this paper.

Authors' contributions: Nan Zhou and Jixiong Zhang participated in the design of this study; Yinan Yao and Hao Yan contributed to writing this manuscript and organizing all the experiments; Cunli Zhu contributed to the field sampling; Nan Zhou and Cunli Zhu contributed to drafting the manuscript; Yinan Yao and Meng Li contributed to analyzing the data; Jixiong Zhang and Nan Zhou reviewed the final paper and made important suggestions and recommendations for paper.

\section{Introduction}

As an environment-friendly coal mining method, sand-based cemented backfill (SCB) technology is widely used to control rock strata under buildings, railways, and water bodies (Behera SK et al. 2019). However, in SCB mining below water bodies and above the confined water, the adjacent aquifers can be damaged. As a result, groundwater permanently seeps into the goaf through the water-conducting fissures, soaking the backfill and deteriorating its performance. This long-term deterioration process inevitably affects the aquifers and the surface deformation control effect (Zhou $\mathrm{N}$ et al. 2019; Yan H et al. 2021). Therefore, it is necessary to study SCB's permeability under triaxial compression (which corresponds to mining conditions), improve the waterproof performance of $\mathrm{SCB}$, and reduce the groundwater effect on $\mathrm{SCB}$. Such efforts are essential for strengthening the long-term stability of SCB and enhancing the safety of SCB mining (Tibbetts CM et al. 2021).

Numerous studies on the permeability of cemented backfills, as well as coal and rock masses, have been conducted worldwide. Thus, Abdul-Hussain studied the unsaturated hydraulic conductivity and durability against erosion in cemented backfill composed of tailings, adhesive, and sodium silicate as an additive. The results showed that as the adhesive content and the degree of hydration increased, the cemented backfill's unsaturated hydraulic conductivity dropped (AbdulHussain N et al. 2011). Fall and Adrien explored the effects of curing temperature and time on the cemented backfill's permeability composed of tailings and cement. They reported that the 
permeability dropped with curing temperature and time, which decreasing pattern was the most pronounced at the early stage (Fall M et al. 2009). Fan and Liu performed a numerical simulation of permeability evolution for the compacted rock masses based on the cubic law. They also built the permeability evolution model, which was verified by a simulation experiment (Fan L and Liu S 2017). Zhang carried out permeability tests of marble and calcite samples, which proved that the samples' permeability increased dramatically with strain (Zhang SQ et al. 1994). Hamiel analyzed the non-linear features, expansion features, and changes in pore water pressure of rock samples under the shear effect (Hamiel Y et al. 2005). Noteworthy is that the above studies and many similar ones were dedicated to cemented backfill's permeability composed of tailings and gangues as aggregates. However, SCB, which uses aeolian sand as mandatory aggregate, differs significantly from the conventional cemented backfill in particle size and gradation. The contents of cementing materials and additives also have a different impact on SCB's permeability as compared with the conventional cemented backfill. At present, there is still a lack of studies on the relationship between SCB's permeability and its microstructural parameters, as well as the sensitivity of SCB's permeability to different influencing factors.

In this study, SCB mining practice in Jinniu Coal Mine in Yulin, Shaanxi Province of China, was used as an engineering background. The effects of varying contents of cement, fly ash, quicklime, and water reducing agent (WRA) on the permeability of $\mathrm{SCB}$, where aeolian sand was added as aggregate, were studied. Different influencing factors of SCB's permeability were ranked in the descending order of their influence degree. Finally, the influence laws of porosity, pore size, and surface structure on SCB s permeability were analyzed from the microstructural standpoint. The research results are considered instrumental in improving the waterproof performance of SCB and ensuring more safe SCB mining under similar geological conditions.

\section{Materials and Method}

\subsection{Raw materials}

SCB samples used in the experiments were mainly composed of aeolian sand, ordinary Portland Cement P.O 42.5, desulfurized fly ash, quicklime, and water reducing agent (WRA).

(1) The particle size distribution of raw materials

The particle size distribution of raw materials was determined via a Winner3009B Intelligent Laser Particle Size Analyzer. The results are plotted in Fig.1. 
90

91

92

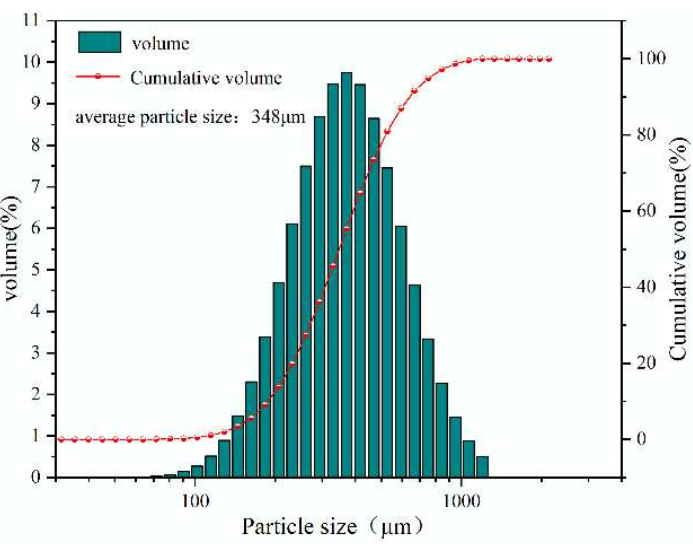

(a) Aeolian sand

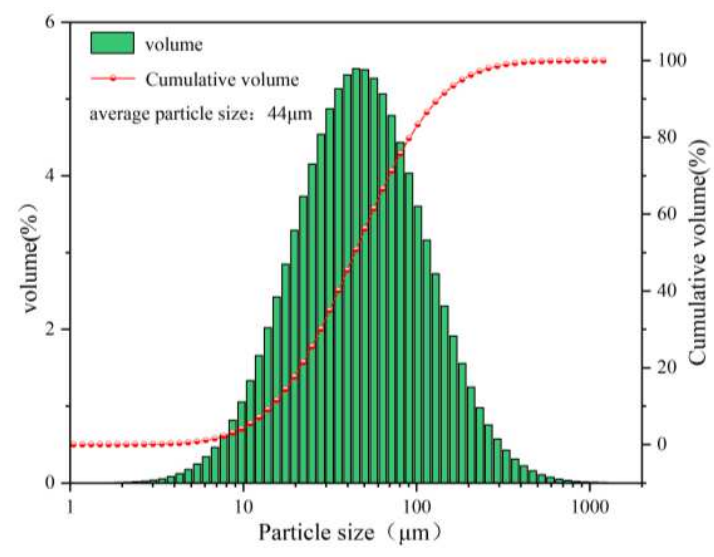

(c) Fly ash

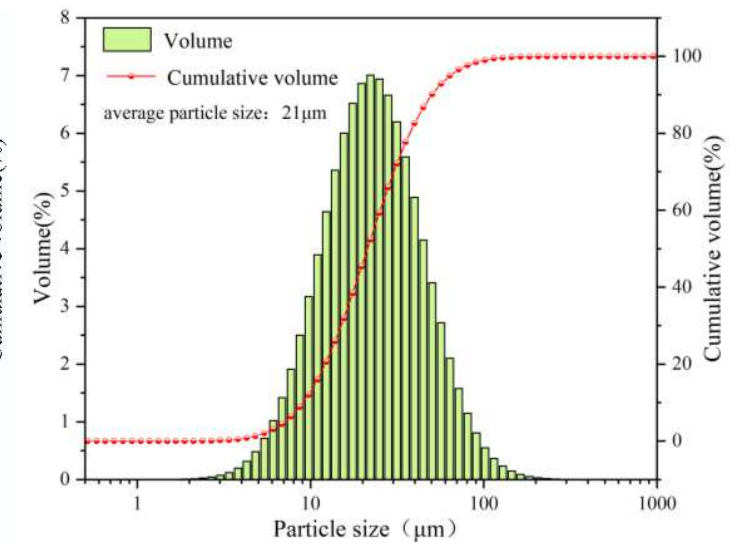

(b) Cement

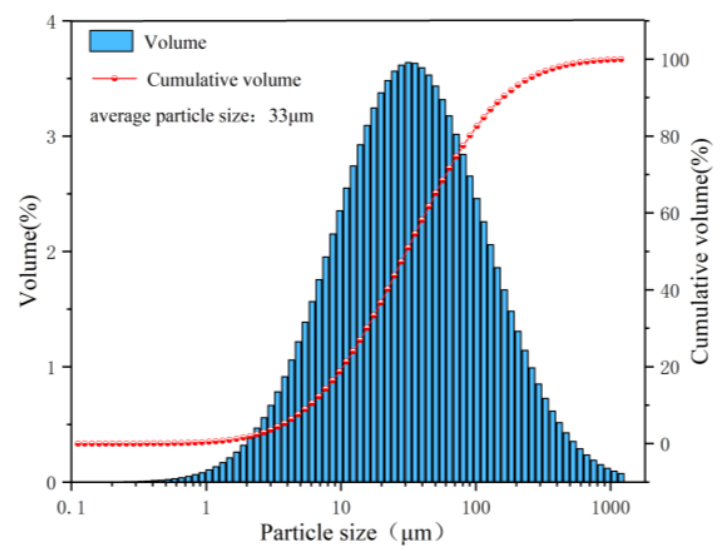

(d) Quicklime

Fig. 1. The particle size distribution of the SCB raw materials.

As shown in Fig. 1 (a), the primary pore sizes of aeolian sand varied between 188 and $638 \mu \mathrm{m}$, with an average of $348 \mu \mathrm{m}$. A small range of particle size distribution indicated that aeolian particles were refined and uniform, which was conducive to particles' adhesion and reduced the permeability (Zhou $\mathrm{N}$ et al. 2019). As shown in Fig. 1 (b), cement's primary particle sizes varied between 9 and $50 \mu \mathrm{m}$, with an average of $21 \mu \mathrm{m}$. The particle size was distributed within a small range, and the gradation curve showed a small dispersion. A smaller particle size resulted in a larger specific surface area, which implied that more free water would be consumed to moisten the material $(\mathrm{Bu}$ YH et al. 2021; Zhang BL et al. 2018). According to Fig. 1 (c), fly ash's primary pore sizes varied between $14 \mu \mathrm{m}$ and $133 \mu \mathrm{m}$, with an average of $44 \mu \mathrm{m}$. Thus, the particle size was distributed over a larger range, and the respective curve featured a larger dispersion. According to Fig. 1 (d), quicklime's primary pore sizes varied between 6 and $158 \mu \mathrm{m}$, with an average of $33 \mu \mathrm{m}$. Thus, the particle size was distributed over a larger range, resulting in non-uniform compactness of SCB (Zhang TS et al. 2011). 

the surface structure of raw materials and evaluate its possible effect on the SCB's permeability.

111

112

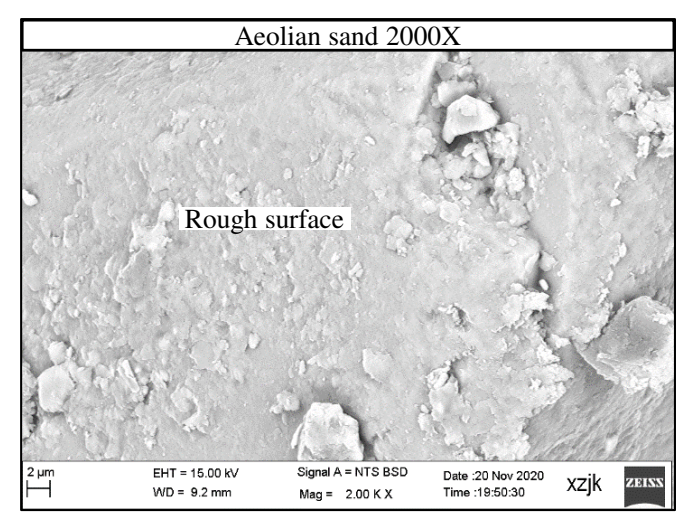

(a) Aeolian sand

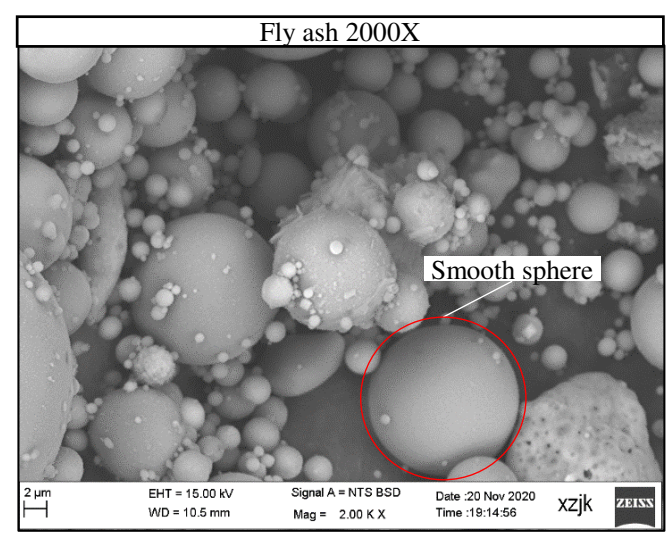

(c) Fly ash

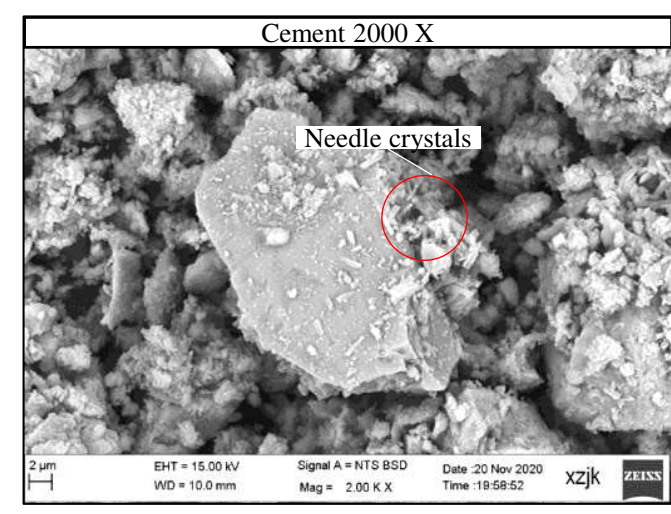

(b) Cement

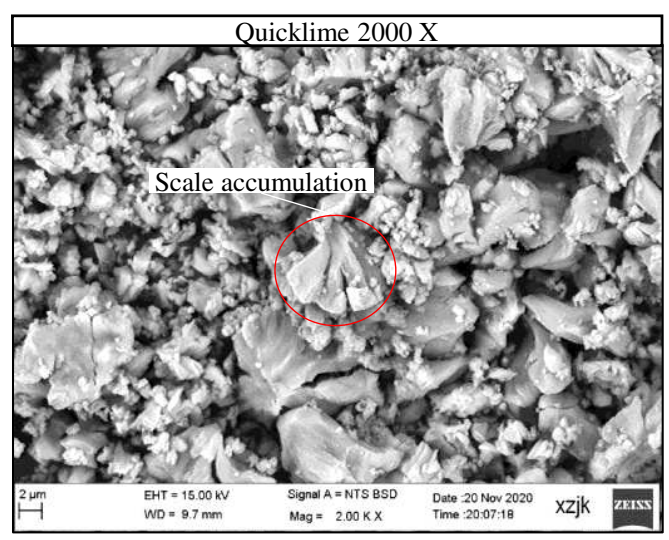

(d) Quicklime

Fig. 2. SEM images of the raw materials

As shown in Fig.2 (a), the aeolian sand particles were dense and generally had rough surfaces without pores or fissures. Such surface structure was conducive to the adherence and bonding of cementing materials and reduced the SCB's permeability. According to Fig.2 (b), many scraps adhered to the surfaces of cement particles. Some of them were rod-like hydration products. Many fibrous or reticulate hydration products linked the aeolian sand particles (Benyamina S et al. 2019; Howladar MF et al. 2015). It can be seen from Fig. 2 (c) that the fly ash was composed of a large number of spheres of varying sizes that aggregated together or were dispersed. The glass microspheres in the fly ash had dense, smooth surfaces. Insufficient hydration would result in the formation of round holes, reducing the SCB compactness. According to Fig. 2 (d), quicklime was composed of scaly stacks' agglomerations, with many irregular scraps adhered to their surfaces 


\subsection{Test procedures}

The multi-factor experiments on SCB samples with different mix ratios consisted of three parts:

(i) sample preparation and pretreatment; (ii) permeability tests and analysis of their results; and (iii) microstructural examination and analysis. The main test procedures are schematically presented in

Fig. 3.

132

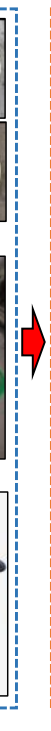

Preparation of experimental materials

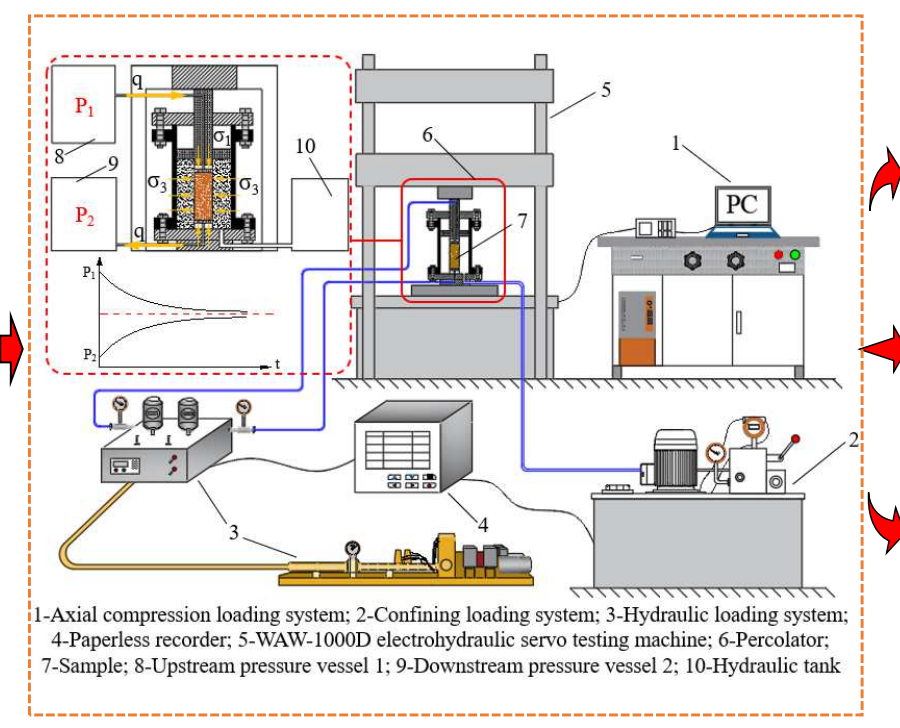

Permeability experiment and analysis

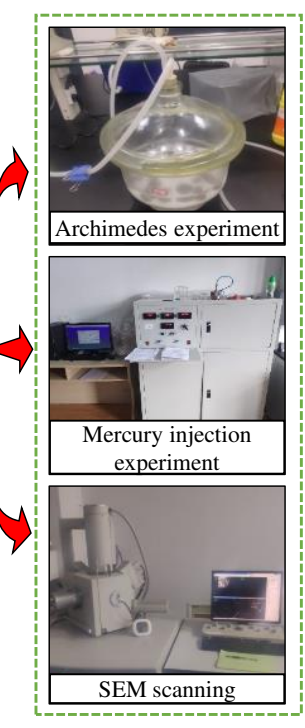

Meso-scale experiment and analysis

Fig. 3. Schematic diagram of test procedures

(1) Sample preparation and preprocessing

Aeolian sand, fly ash, cement, quicklime, and water reducing agent were mixed at different mix ratios. Then water was added. The mixture was prepared into a cemented backfill paste (CBP) using an NJ-160A cement paste mixer. After that, $\mathrm{CBP}$ was poured into a cylindrical mold of $50 \mathrm{~mm}$ in diameter and $100 \mathrm{~mm}$ in height. CBP was fully shaken via a shaker for 1-2 min to make it compact and repel the air bubbles. The mold was removed after leaving the CBP to stand for $24 \mathrm{~h}$. The cylindrical samples were placed into a curing box to cure for 28 days. The specimens were cured and then cut and polished with a cutting machine and a polishing machine, respectively. It was ensured that the flatness of the two end surfaces was below $0.5 \mathrm{~mm}$ and their parallelism was below $0.02 \mathrm{~mm}$, which satisfied the Standard for Tests Method of Engineering Rock Masses (GB5021894). After the above surface treatment, the samples were soaked in the water to make them watersaturated.

(2) Permeability test 
Before the test, the upper and lower rams holding the sample and a porous plate were wrapped up together with tape into a waterproof and heat-shrinkable sleeve. It was then placed into the groove at the bottom of the seepage meter, and the groove was capped. An axial pressure was applied to the sample. Water was injected into two pressurized vessels of the hydraulic pressure loading system 3 in Fig. 3. A specific pressure difference was ensured between the two vessels. The inlet and outlet pipes were connected to the corresponding joints of the seepage meter. Each joint's tightness was checked, and a closed channel filled with water was formed between the seepage meter and the vessels. After the test was started, water in the two pressurized vessels entered the inlet and the outlet pipes simultaneously. Therefore, a difference in hydraulic pressure was created between the inlet and outlet pipes (and, thus, between the upper and lower surfaces of the sample). The hydraulic pressure levels were monitored on the real time scale via the pressure gauge and the pressure transmitter, whose readings were recorded by the data collection and analysis system.

The SCB samples' permeability was calculated as follows:

$$
K=\frac{c_{f} V H \mu}{2 t_{f} A} \ln \left(\frac{p_{10}-p_{20}}{p_{1 f}-p_{2 f}}\right),
$$

where $c_{f}$ is the coefficient of volume compressibility of the fluid, which was taken as $4.85 \times 10^{-3}$ in this study; $V$ is the volume of the voltage stabilizer; $H$ is the sample height, taken as $100 \mathrm{~mm} ; \mu$ is the dynamic viscosity of the seeping fluid (water), taken as $0.89 \times 10^{-3} \mathrm{~Pa} . \mathrm{s}$ for $25^{\circ} \mathrm{C}$; $t_{f}$ is the end time of equidistant sampling; $A$ is the cross-sectional area of the sample, taken as $1.96 \times 10^{3} \mathrm{~mm}^{2} ; P_{10}$ and $P_{20}$ are the initial pressures of vessels 1 and 2 in the upstream and the downstream, respectively; $P_{1 f}$ and $P_{2 f}$ are the final pressures acting on vessels 1 and 2 in the upstream and the downstream at the end time, respectively.

(3) Microstructural examination

The influencing factors of SCB's permeability were analyzed on a microscopic scale. The Archimedes method, mercury intrusion porosimetry, and SEM scanning were employed to detect the porosity, pore size, and surface structure of SCB. Using the Archimedes method, the sample block mass $m_{1}$ was weighed after drying for $12 \mathrm{~h}$. The mass $m_{2}$ was weighed after sealing and gas extraction for $2 \mathrm{~h}$ plus immersion in the distilled water for $12 \mathrm{~h}$. The mass $m_{3}$ was weighed after wiping off the water. Thus, the porosity $n$ was the ratio of the mass of fluid seeping into the pores to that of fluid displaced by the sample: 


$$
\mathrm{n}=\frac{m_{3}-m_{1}}{m_{3}-m_{2}}
$$

177 where $m_{1}, m_{2}$, and $m_{3}$ are masses of the sample block after the described above procedures.

178 The mercury intrusion porosimetry was implemented by a YG-97A capacitive mercury 179 injection apparatus. The maximum pressure imposed by the apparatus was $60 \mathrm{MPa}$. The measurable

180 range of pore size of the samples was 0.016 to $63 \mu \mathrm{m}$, with a precision of $0.5 \%$ (Fridjonsson EO et al. 2013). The surface structure was observed by SEM scanning using a Zeiss Sigma-HV FE-SEM. The samples were dried at a constant temperature of $40^{\circ} \mathrm{C}$ for $12 \mathrm{~h}$ and then crushed. Smaller samples with $10 \mathrm{~mm} \times 10 \mathrm{~mm} \times 5 \mathrm{~mm}$ dimensions were harvested from inside the larger sample blocks. With the natural face formed by crushing facing upwards, the sample was fixed to the base using conductive adhesive or glue, followed by gold spraying.

\subsection{Design of the experimental scheme}

The mass of the aeolian sand was a fixed value. The contents of other ingredients were expressed as the ratio of mass to that of the aeolian sand. With all other factors being constant, the level of one factor was changed at a time for univariate analysis. Four groups (A, B, C, and D) of samples were prepared to detect the effect of each factor on SCB's permeability. Different contents of each ingredient were set up: $60,70,80$, and $90 \%$ for fly ash; $5,10,15$, and $20 \%$ for cement and quicklime; and $0.1,0.2,0.3$, and $0.4 \%$ for water reducing agent (WRA). The mix ratios of raw materials are listed in Table 1. As seen in Table 1, four levels were set up for each of the four factors, and 16 tests were performed under a total of 13 mix ratios, insofar as three samples $\left(\mathrm{B}_{3}, \mathrm{C}_{3}\right.$, and $\left.\mathrm{D}_{4}\right)$ were identical to the standard sample $\mathrm{A}_{2}$, with fly ash content of $70 \%$, cement content of $15 \%$, quicklime content of $15 \%$, and WRA content of $0.4 \%$.

Table 1. Permeability test schemes for SCB samples with different mix ratios

\begin{tabular}{|c|c|c|c|c|c|c|}
\hline \multirow{2}{*}{ Test group } & \multirow{2}{*}{$\begin{array}{c}\text { Mix } \\
\text { number }\end{array}$} & \multicolumn{4}{|c|}{ Percentage of dry material, $\%$} & \multirow{2}{*}{$\begin{array}{c}\text { Concentration } \\
(\%)\end{array}$} \\
\hline & & Fly ash, \% & Cement, \% & Quicklime, \% & WRA, $\%$ & \\
\hline & $\mathrm{A}_{1}$ & 60 & 15 & 15 & 0.4 & \multirow{14}{*}{78} \\
\hline A & $\mathrm{A}_{2}{ }^{*}$ & 70 & 15 & 15 & 0.4 & \\
\hline \multirow{3}{*}{ (Fly ash) } & $\mathrm{A}_{3}$ & 80 & 15 & 15 & 0.4 & \\
\hline & $\mathrm{A}_{4}$ & 90 & 15 & 15 & 0.4 & \\
\hline & $\mathrm{B}_{1}$ & 70 & 5 & 15 & 0.4 & \\
\hline B & $\mathrm{B}_{2}$ & 70 & 10 & 15 & 0.4 & \\
\hline \multirow[t]{3}{*}{ (Cement) } & $\mathrm{B}_{3}{ }^{*}$ & 70 & 15 & 15 & 0.4 & \\
\hline & $\mathrm{B}_{4}$ & 70 & 20 & 5 & 0.4 & \\
\hline & $\mathrm{C}_{1}$ & 70 & 15 & 5 & 0.4 & \\
\hline $\mathrm{C}$ & $\mathrm{C}_{2}$ & 70 & 15 & 10 & 0.4 & \\
\hline \multirow[t]{2}{*}{ (Quicklime) } & $\mathrm{C}_{3}{ }^{*}$ & 70 & 15 & 15 & 0.4 & \\
\hline & $\mathrm{C}_{4}$ & 70 & 15 & 20 & 0.4 & \\
\hline D & $\mathrm{D}_{1}$ & 70 & 15 & 15 & 0.1 & \\
\hline (WRA) & $\mathrm{D}_{2}$ & 70 & 15 & 15 & 0.2 & \\
\hline
\end{tabular}




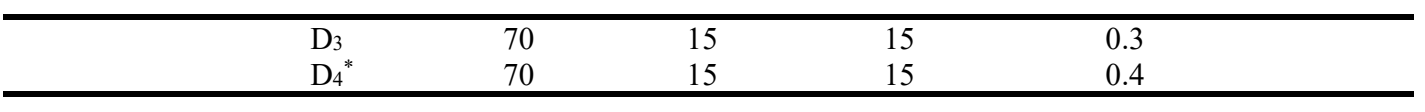

* Note: Cases A2, B3, C3, and D4 correspond to the same test results and, therefore, are identical.

199

200

201

202

203

204

A

(Fly ash)

B

(Cement)

C

(Quicklime)

D

(WRA)

Table 2. SCB's permeability test results for various contents of four raw materials

\begin{tabular}{|c|c|c|c|c|c|c|}
\hline \multirow[t]{2}{*}{ Test group } & \multirow{2}{*}{$\begin{array}{l}\text { Mix } \\
\text { number }\end{array}$} & \multirow{2}{*}{$\begin{array}{l}\text { Analyzed factor's } \\
\text { content, } \%\end{array}$} & \multicolumn{3}{|c|}{$\begin{array}{l}\text { Permeability in } 3 \text { tests } \\
\left(\times 10^{-2} \mathrm{mD}\right)\end{array}$} & \multirow{2}{*}{$\begin{array}{l}\text { Average permeability } \\
\qquad\left(\times 10^{-2} \mathrm{mD}\right)\end{array}$} \\
\hline & & & $\mathrm{K}_{1}$ & $\mathrm{~K}_{2}$ & $\mathrm{~K}_{3}$ & \\
\hline \multirow{5}{*}{$\begin{array}{c}\text { A } \\
\text { (Fly ash) }\end{array}$} & $\mathrm{A}_{1}$ & 60 & 0.584 & 0.961 & 0.773 & 0.773 \\
\hline & $\mathrm{A}_{2}$ & 70 & 2.52 & 2.42 & 5.09 & 3.34 \\
\hline & $\mathrm{A}_{3}$ & 80 & 0.751 & 2.06 & 2.80 & 1.87 \\
\hline & $\mathrm{A}_{4}$ & 90 & 0.854 & 1.36 & 1.48 & 1.23 \\
\hline & $\mathrm{B}_{1}$ & 5 & 3.25 & 1.47 & 3.05 & 2.59 \\
\hline \multirow{4}{*}{$\begin{array}{c}\mathrm{B} \\
\text { (Cement) }\end{array}$} & $\mathrm{B}_{2}$ & 10 & 1.82 & 2.76 & 2.32 & 2.30 \\
\hline & $\mathrm{B}_{3}$ & 15 & 2.52 & 2.42 & 5.09 & 3.34 \\
\hline & $\mathrm{B}_{4}$ & 20 & 1.63 & 4.97 & 5.42 & 4.01 \\
\hline & $\mathrm{C}_{1}$ & 5 & 6.57 & 12.0 & 2.90 & 7.15 \\
\hline \multirow{4}{*}{$\begin{array}{c}\mathrm{C} \\
\text { (Quicklime) }\end{array}$} & $\mathrm{C}_{2}$ & 10 & 1.82 & 6.30 & 6.45 & 4.86 \\
\hline & $\mathrm{C}_{3}$ & 15 & 2.52 & 2.42 & 5.09 & 3.34 \\
\hline & $\mathrm{C}_{4}$ & 20 & 3.04 & 4.28 & 1.69 & 3.00 \\
\hline & $\mathrm{D}_{1}$ & 0.1 & 2.27 & 3.50 & 2.88 & 2.88 \\
\hline \multirow{3}{*}{$\begin{array}{c}\mathrm{D} \\
(\mathrm{WRA})\end{array}$} & $\mathrm{D}_{2}$ & 0.2 & 3.90 & 3.33 & 2.98 & 3.40 \\
\hline & $\mathrm{D}_{3}$ & 0.3 & 3.22 & 3.60 & 2.01 & 2.94 \\
\hline & $\mathrm{D}_{4}$ & 0.4 & 2.52 & 2.42 & 5.09 & 3.34 \\
\hline
\end{tabular}

The averaged results on permeability variation with each ingredient's content are plotted in Fig. 4. 


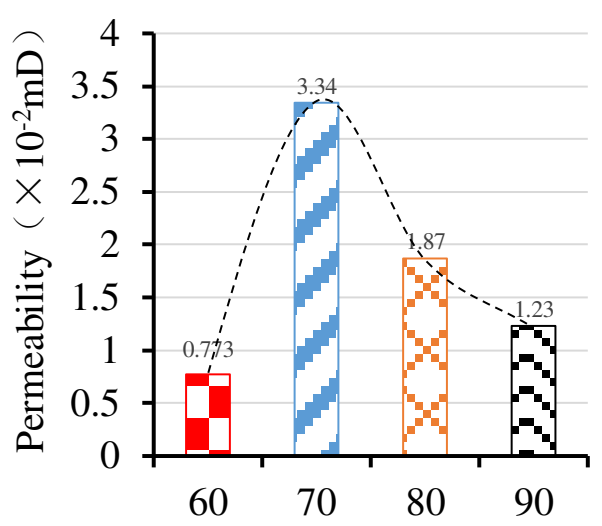

Fly ash content (\%) (a) Fly ash

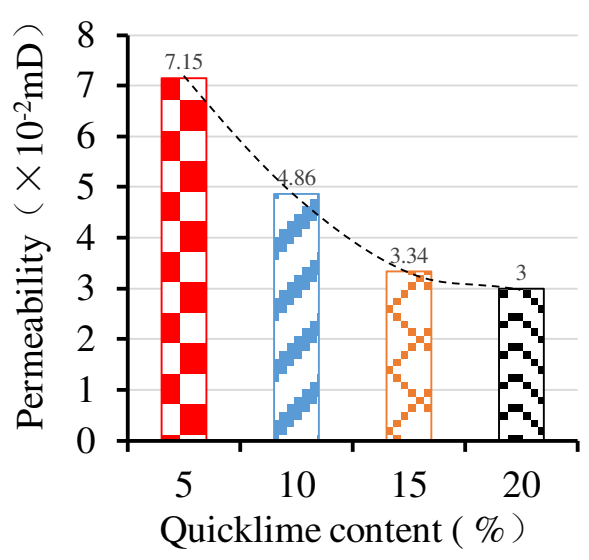

(c) Quicklime

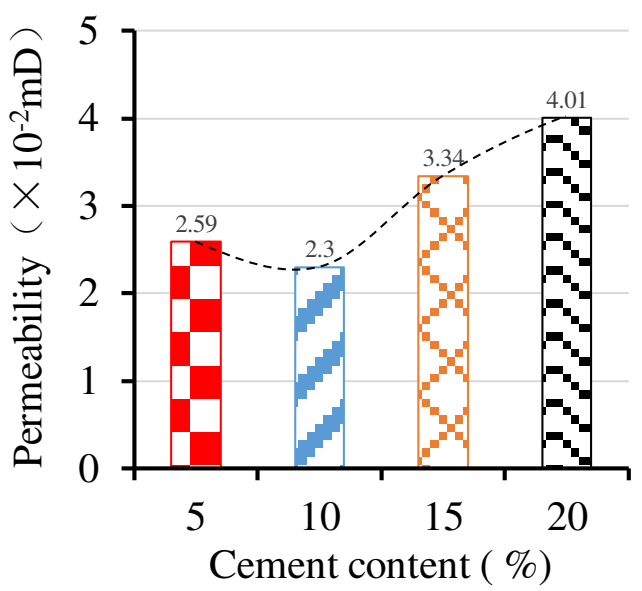

(b) Cement

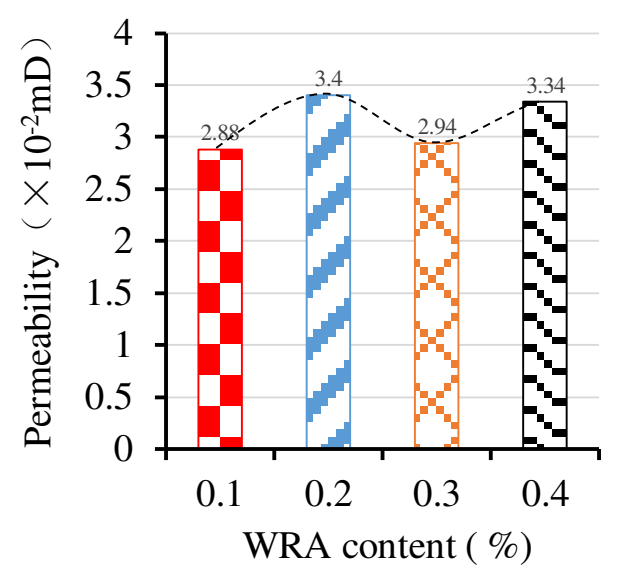

(d) WRA

Fig. 4. Effect of different raw materials' contents on SCB's permeability

As shown in Fig. 4 (a), when the fly ash content was increased from 60 to $90 \%$, the SCB's permeability exhibited a sharp rise, followed by a gradual drop, ranging between $0.773 \times 10^{-2}$ and $3.34 \times 10^{-2} \mathrm{mD}$. A more detailed analysis of Fig. 4(a) revealed that within the fly ash content range between 60 and $70 \%$, the SCB's permeability was highly sensitive to the fly ash content variation, reaching its maximum of $3.34 \times 10^{-2} \mathrm{mD}$ at $70 \%$. After the fly ash content exceeded $70 \%$, both the permeability and the above sensibility decreased. This trend in concert with findings of (Behera SK et al. 2019), which reported that a water film was formed and adsorbed by the spherical surfaces when the fly ash came into contact with water. As the fly ash content increased, the amount of free water consumed by the formation of water film decreased dramatically. Consequently, the hydration of other cementing materials, such as cement, would be incomplete. Given the above, the SCB's permeability increased significantly as the fly ash content grew from 60 to $70 \%$. As the fly ash content reached a certain level, fly ash would act as a fine aggregate, filling pores, enhancing the 
backfill's compactness, and resulting in a gradual permeability decline (Ismail I et al. 2013).

According to Fig. 4 (b), as the cement content increased from 5 to $10 \%$, SCB's permeability exhibited a slight gradual drop. As the cement content was increased from 10 to $20 \%$, the permeability gradually grew at a decreasing rate, reaching its minimum of $2.30 \times 10^{-2} \mathrm{mD}$ at the cement content of $10 \%$. The permeability range was between $2.3 \times 10^{-2}$ and $4.0 \times 10^{-2} \mathrm{mD}$.

Noteworthy is that cement is usually added as the main cementing material in SCB. Cement hydration can give rise to ettringite (AFt) and calcium silicate hydrate (C-S-H), facilitating the bonding of adjacent aeolian sand particles. The cement content of $5 \%$ is considered a too low dose for cementing materials, which fails to ensure the bonding of aeolian sand particles. As the cement content was increased to $10 \%$, the number of hydration products was increased, reducing the SCB permeability. As the cement content further increased to $15 \%$ and $20 \%$, the dry material's specific surface area grew sharply because there were many small-sized particles, which surface moistening consumed a large amount of free water. The fine cement particles could also envelop the water molecules to form a loose flocculent structure, which further led to an increase in permeability (Kwan AKH and Chen JJ 2013; Qureshi T et al. 2018).

According to Fig. 4(c), as the quicklime content increased from 5 to $20 \%$, SCB's permeability showed a decreasing trend, and this drop was slowed down gradually. SCB's permeability varied more significantly as the quicklime content increased. The variation range was from $3.0 \times 10^{-2}$ to $7.1 \times 10^{-2} \mathrm{mD}$. Noteworthy is that $\mathrm{CaO}$ in the quicklime is hygroscopic, and its hydration gives rise to $\mathrm{Ca}(\mathrm{OH})_{2}$, which can facilitate the hydration of glass microspheres in fly ash (Panchal $\mathrm{S}$ et al. 2018). In this study, increasing the quicklime content reduced the migration of excess free water during the preparation of SCB samples, reducing the backfill's microsphere loss. As a result, the SCB became more compact, and its permeability dropped with the quicklime content.

As shown in Fig. 4 (d), as the water reducing agent content increased from 0.1 to $0.4 \%$, the SCB's permeability varied slightly and tended to stabilize. The permeability ranged between $2.9 \times 10^{-}$ ${ }^{2}$ and $3.3 \times 10^{-2} \mathrm{mD}$. On the one hand, water reducing agent adhered to the surface of cement particles, causing repulsion between like charges and reducing the enveloping effect offered by cement particles to free water. Therefore, the raw materials came into full contact with free water, facilitating the hydration (Mucsi G et al. 2013; Sun Q et al. 2020). On the other hand, the WRA enveloping effect reduced cement's hydration, as the main cementing material, at the early stage (Chen SJ et al. 
253 2020). Taken together, changes in WRA content had no significant impact on SCB's permeability.

2543.2 Correlation analysis between SCB's microscopic structure and permeability

255 3.2.1 Porosity

256 The influence of the contents of fly ash, cement, quicklime, and water reducing agent on SCB's

257 permeability was verified by measuring the corresponding changes in porosity. The porosity $(n)$ of

258 each sample was assessed by the Archimedes method via Eq.(2). The test results are shown in Table

2593 and Fig. 5.

Table 3. Porosity test results via the Archimedes method

\begin{tabular}{ccccccc}
\hline \multirow{2}{*}{ Test group } & $\begin{array}{c}\text { Mix } \\
\text { number }\end{array}$ & $\begin{array}{c}\text { Dry } \\
\text { weight, } g\end{array}$ & $\begin{array}{c}\text { Sample weight in the } \\
\text { fluid, } g\end{array}$ & $\begin{array}{c}\text { Wet } \\
\text { weight, } g\end{array}$ & $\begin{array}{c}\text { Total sample } \\
\text { volume, } \mathrm{cm}^{3}\end{array}$ & $\begin{array}{c}\text { Porosity } \\
n, \%\end{array}$ \\
\hline A & A1 & 5.43 & 2.90 & 5.48 & 2.59 & 2.25 \\
(Fly ash) & A2 & 10.83 & 5.20 & 11.08 & 5.89 & 4.32 \\
& A3 & 9.43 & 4.13 & 9.60 & 5.49 & 3.12 \\
& A4 & 4.77 & 2.22 & 4.82 & 2.61 & 1.91 \\
B & B1 & 5.55 & 2.72 & 5.68 & 2.97 & 4.35 \\
(Cement) & B2 & 6.17 & 2.98 & 6.30 & 3.33 & 4.07 \\
& B3 & 10.83 & 5.20 & 11.08 & 5.89 & 4.32 \\
& B4 & 9.13 & 4.09 & 9.41 & 5.33 & 5.27 \\
C & C1 & 6.66 & 3.23 & 6.90 & 3.68 & 6.53 \\
(Quicklime) & C2 & 9.03 & 4.25 & 9.26 & 5.02 & 4.73 \\
& C3 & 10.83 & 5.20 & 11.08 & 5.89 & 4.32 \\
& C4 & 8.61 & 4.04 & 8.77 & 4.74 & 3.51 \\
& D1 & 9.78 & 4.66 & 10.03 & 5.38 & 4.58 \\
D & D2 & 6.74 & 3.30 & 6.91 & 3.62 & 4.76 \\
(WRA) & D3 & 10.13 & 4.97 & 10.37 & 5.41 & 4.52 \\
& D4 & 10.83 & 5.20 & 11.08 & 5.89 & 4.32 \\
\hline
\end{tabular}

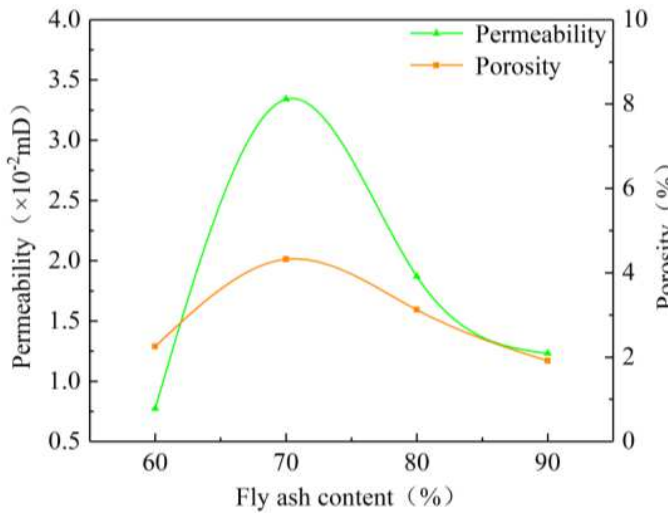

(a) Fly ash

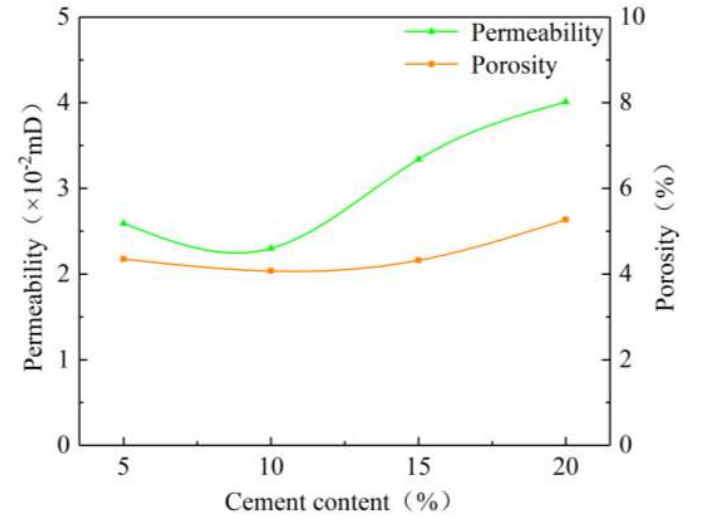

(b) Cement

(2) 


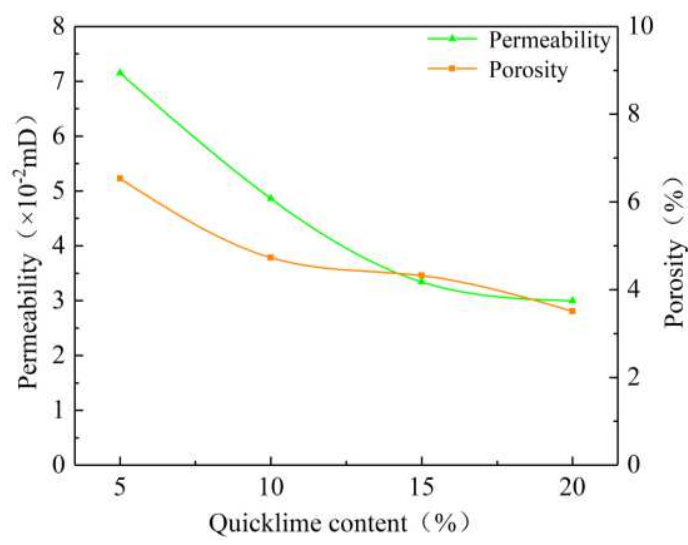

(c) Quicklime

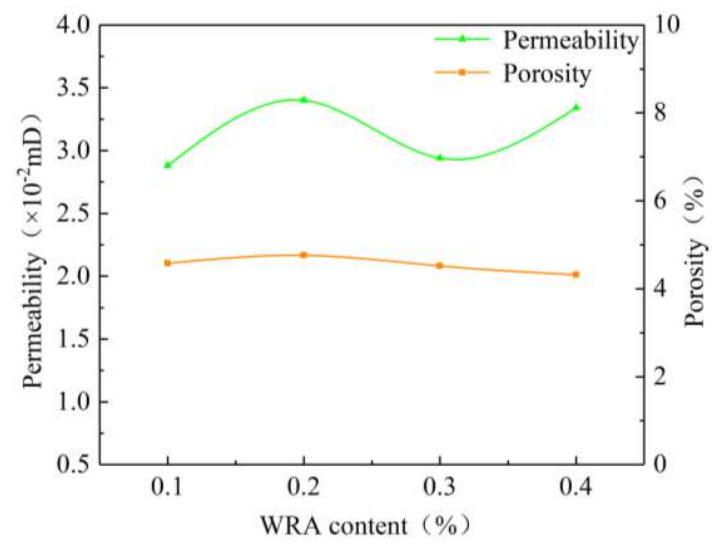

(d) WRA

Fig. 5. Effect of different raw materials' content on the permeability and porosity of SCB

As shown in Fig. 5, the variation curve of the overall porosity of SCB for various contents of raw materials coincided well with the variation curve of permeability. As shown in Fig. 5 (a), SCB's permeability and porosity reached their maxima at the fly ash content of $70 \%$. In Fig. 5 (b), the porosity curve was less steep than the permeability one, though both curves shared a consistent trend. According to Fig. 5 (c), both permeability and porosity dropped with the quicklime content and nearly coincided at the last stage. As seen in Fig. 5 (d), WRA content had a very slight effect on SCB's porosity, which was earlier explained.

Thus, SCB's porosity ranged between 1.91 and $6.53 \%$ under different contents of raw materials and closely correlated with the permeability variation.

\subsubsection{Particle size effect on permeability}

The relationships of SCB's permeability with pore distribution, pore size, and mix ratio were analyzed. The pore size distributions of each sample are shown in Fig. 6.

As seen in Fig. 6 (a), the permeability reached its maximum at the fly ash content of $70 \%$. The primary pore sizes (top three pore sizes in terms of occurrence frequency) were $0.25-0.63 \mu \mathrm{m}$, accounting for $53.5 \%$ of the total pore size. At fly ash contents of 60,80 , and $90 \%$, the primary pore sizes of SCB significantly exceeded those at $70 \%$, ranging between 0.16 and $0.4 \mu \mathrm{m}$ and accounting for $51.2,49.8$, and $51.7 \%$ of the total pore size, respectively. Thus, within the fly ash content range from 60 to $90 \%$, SCB's primary pore sizes positively correlated with permeability values: larger primary pore sizes corresponded to higher permeability values and vice versa. 
285

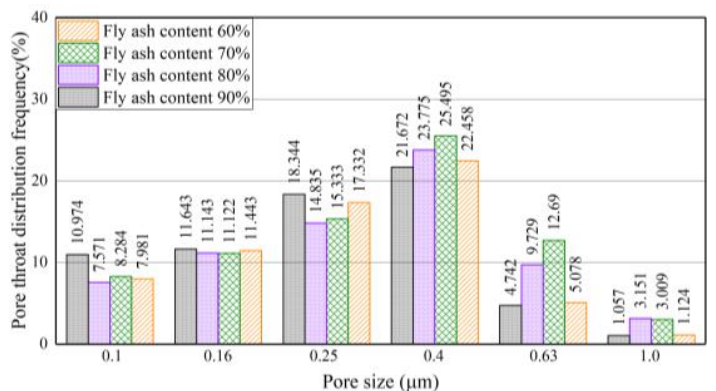

(a) Fly ash

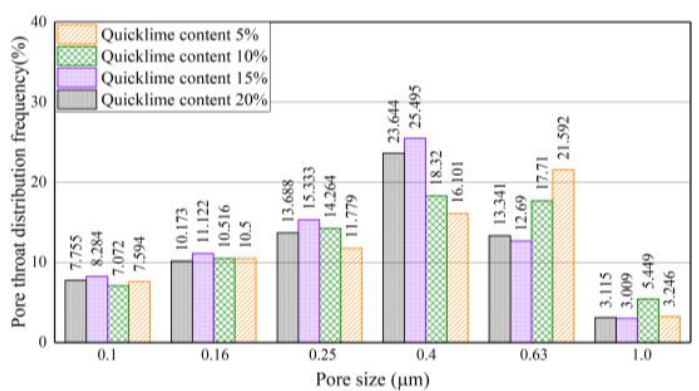

(c) Quicklime

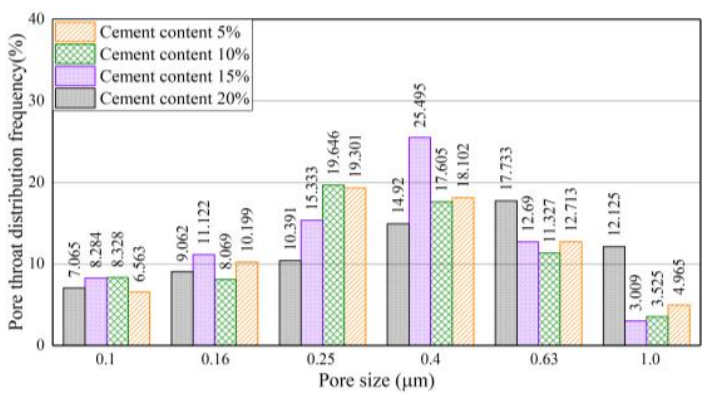

(b) Cement

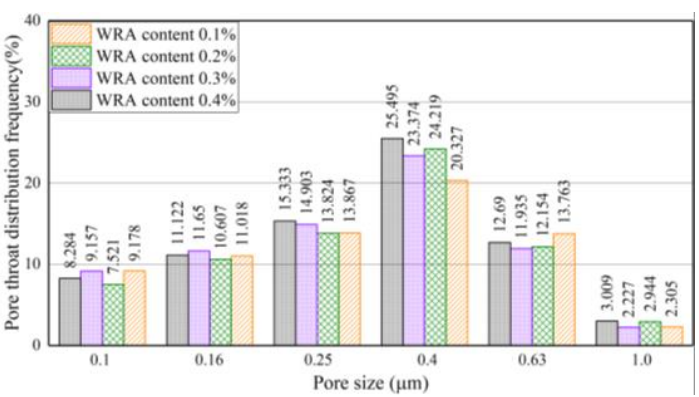

(d) WRA

Fig. 6. Histogram of the particle size distribution of SCB samples with different contents of raw materials

According to Fig. 6 (b), when the cement content was 5, 10, and 15\%, the primary pore sizes of SCB ranged between 0.25 and $0.63 \mu \mathrm{m}$. The primary pore sizes for cement contents of 5 and $10 \%$ accounted for 50.1 and $48.6 \%$ of the total pore sizes, respectively. The difference between the two was small, and so was the corresponding permeability change. The pore size of 0.4 um accounted for the highest proportion (about 25.49\%) for the cement content of 15\%; the proportion of pore size of $0.25 \mu \mathrm{m}$ dropped from $19.65 \%$ at the cement content of 10 to $15.33 \%$, corresponding to that of $15 \%$. The share of large-sized pores at the cement content of $15 \%$ exceeded those at 5 and $10 \%$.

The permeability also increased correspondingly. At the cement content of $20 \%$, the primary pore sizes were distributed in the range from 0.4 to $1 \mu \mathrm{m}$, which significantly exceeded those of all other contents. The corresponding permeability was also the highest. The above results indicated that the cement content variation between 5 to $10 \%$ had a relatively small impact on the pore size distribution of $\mathrm{SCB}$, in contrast to that in the range from 10 to $20 \%$. Generally speaking, the primary pore sizes of SCB correlated more closely with permeability within the cement content range from 5 to $20 \%$.

As seen in Fig. 6 (c), the primary pore sizes of SCB at quicklime contents of 5, 10, and 15\% were within the range from 0.25 to $0.63 \mu \mathrm{m}$. However, the share of pores with a size of $0.63 \mu \mathrm{m}$ gradually decreased with quicklime content, accounting for $21.60,17.71$, and $12.69 \%$ of the total 
pore size for quicklime contents of 5, 10, and 15\%, respectively. At the quicklime content of $20 \%$, the distribution of primary pore sizes differed little from that of $15 \%$ quicklime content. The permeability dropped with the quicklime content and exhibited a saturation. Thus, when the quicklime content was in the range from 5 to $20 \%$, SCB's primary pore sizes positively correlated with permeability: the smaller the primary pore sizes, the lower the permeability. If the primary pore sizes remained unchanged, the corresponding permeability tended to stabilize.

The analysis of Fig. 6 (d) revealed that when the WRA content ranged from 0.1 to $0.4 \%$, the primary pore sizes of SCB ranged between 0.25 and $0.63 \mu \mathrm{m}$. Although the share of pores with a size of $0.4 \mu \mathrm{m}$ fluctuated, this pore size consistently accounted for the highest proportion. Meanwhile, the permeability changed less significantly and tended to stabilize. The above results indicated that within the WRA content range from 0.1 to $0.4 \%$, SCB's primary pore sizes closely correlated with permeability. However, the WRA content had a weaker effect on SCB's pore size distribution.

\subsubsection{Surface structure}

The evolution law of SCB's microstructure and its effect on permeability were studied under different mix ratios. SCB samples with different contents of fly ash, cement, quicklime, and WRA were examined by SEM. The observations with the magnification power of 5000X are shown in Fig. 7. According to Fig. 7 (a), with fly ash contents of $60,70,80$, and 90\%, SCB's permeability first increased and then decreased as the fly ash content increased. The permeability reached its maximum at the fly ash content of $70 \%$. According to the SEM images, at the fly ash content of $60 \%$, the smallest pore sizes were observed on the SCB surface. These pores were mostly quasicircular or polygonal in shape. The hydration of cementing materials was more significant, leading to higher overall compactness and lower permeability of SCB. When the fly ash content increased from 60 to $70 \%$, the pore sizes on the SCB surface increased dramatically and cementing materials' hydration was incomplete. As a result, the aeolian sand particles could not be sufficiently bound to each other. The pores were mostly polygonal and strip-like, and SCB had a loose overall structure and larger permeability (Zhao HT et al. 2020). At fly ash contents of 80 and $90 \%$, the pore size gradually dropped, according to the SEM images in Fig 7(a). A large number of scraps filled the pores, reducing the SCB permeability. 
334

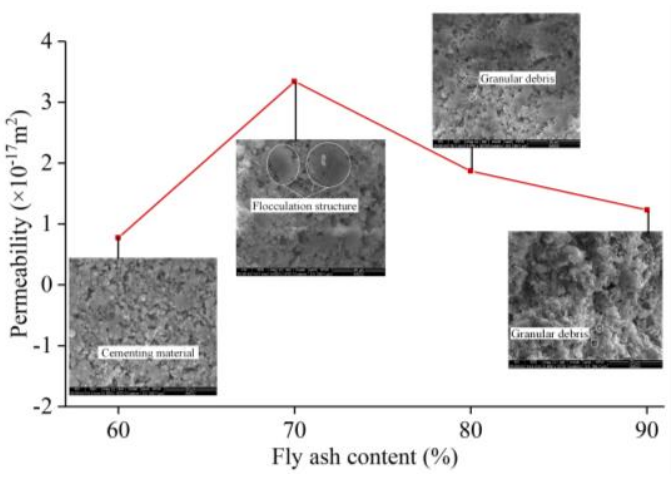

(a) Fly ash

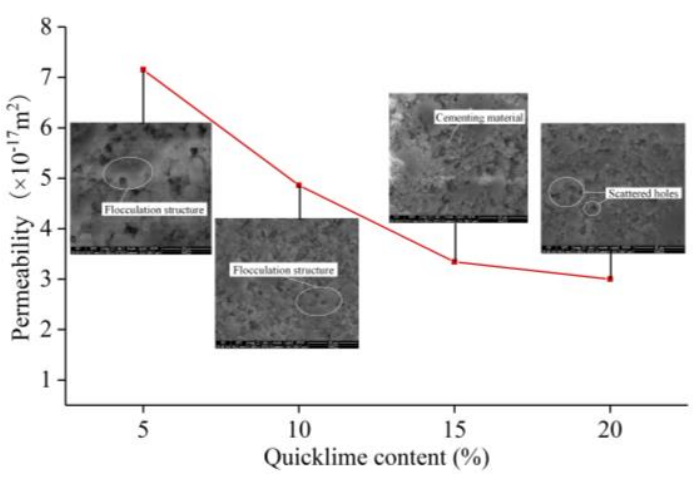

(c) Quicklime

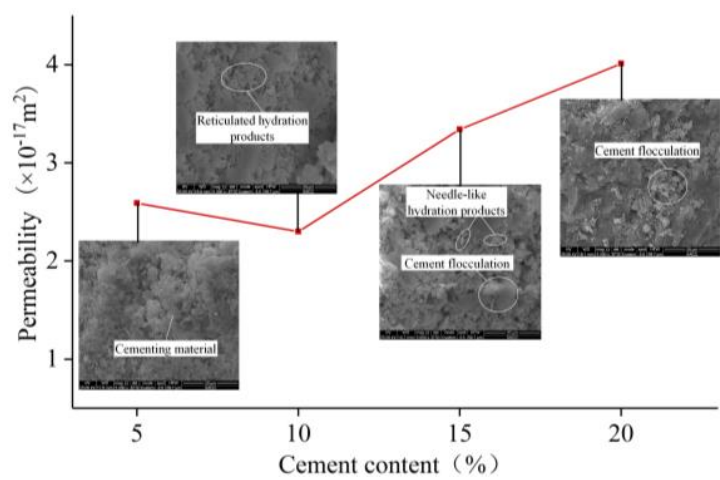

(b) Cement

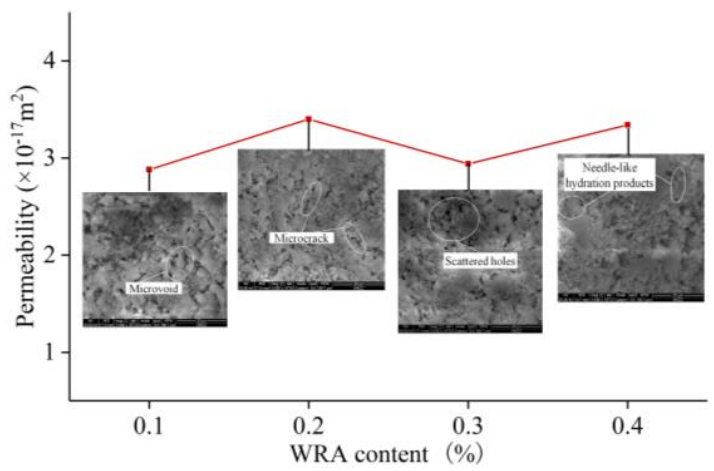

(d) WRA

Fig. 7. SEM images of SCB samples with different mix ratios of fly ash, cement, quicklime, and WRA.

In Fig. 7 (b), under the cement content of 5, 10, 15, and 20\%, SCB's permeability first dropped and then gradually rose as the cement content increased. It can be seen from the SEM images that at the cement content of $10 \%$, there were more cemented materials on the surface than at $5 \%$. Pores and fissures were smaller, and the overall structure was more compact. Correspondingly, the permeability was lower (Alfonso I et al. 2019). When the cement content grew to 15 and $20 \%$, there were many cement flocs due to incomplete hydration. A larger amount of free water was enveloped at higher cement contents, which inhibited the hydration. Fewer cemented materials were produced, pores were larger, and the overall structure was looser. Therefore, the permeability gradually increased(Liu J et al. 2014; Zhou W et al. 2020).

As shown in Fig. 7 (c), the permeability gradually dropped with quicklime content at quicklime contents of $5,10,15$, and $20 \%$. The pore sizes had a wider distribution wider range in the respective SEM images, decreasing gradually during this process. Moreover, the amount of cemented materials produced gradually increased, indicating a higher degree of hydration and a looser SCB structure. Such variations were consistent with the permeability changes.

According to Fig. 7 (d), SCB's permeability varied little at WRA contents of 0.1, 0.2, 0.3, and 
$0.4 \%$ and tended to stabilize. In the respective SEM images, pore sizes of the SCB surface were small at any WRA content. The pore shape and pore size distribution density were also similar at different WRA contents. Thus, changes in the WRA content had little impact on SCB's surface structure and permeability.

\subsection{Sensitivity analysis of multiple influencing factors}

The so-called range analysis was adopted in this study due to its simplicity, rapidity, conciseness, and efficiency (Chen JJ et al. 2020). This approach implies that the overall response $K_{i j}$ under different levels of each factor (where $i$ is the level and $j$ is the factor) is calculated. The average $\bar{K}_{\mathrm{ij}}$ is taken and used to calculate the range $(R)$ of the corresponding indicator under different levels of factors. Factors are ranked in the descending order of $R$-value, which is used to indicate the influence degree.

Such range analysis was performed for SCB's permeability under different mix ratios, as shown in Table 4.

Table 4. Results of the range analysis of SCB's permeability under different contents of raw materials

\begin{tabular}{ccccc}
\hline \multirow{2}{*}{ Indicator } & \multicolumn{3}{c}{ SCB's permeability for various contents of raw materials $\left(\times 10^{-17} \mathrm{mD}\right)$} \\
& Fly ash & Cement & WRA & WRe \\
\hline $\bar{K}_{1 \mathrm{j}}$ & 0.77 & 2.59 & 7.15 & 2.88 \\
$\bar{K}_{2 \mathrm{j}}$ & 3.34 & 2.30 & 4.86 & 3.40 \\
$\bar{K}_{3 \mathrm{j}}$ & 1.87 & 3.34 & 3.34 & 2.94 \\
$\bar{K}_{4 \mathrm{j}}$ & 1.23 & 4.01 & 3.00 & 3.34 \\
$R_{m}$ & 2.57 & 1.71 & 4.15 & 0.52 \\
\hline
\end{tabular}

Next, the factors were ranged in terms of their influence degree. Each factor was plotted along the $x$-axis and the range along the $y$-axis. The influence degree of each factor on SCB's permeability was thus visualized in Fig. 8. 


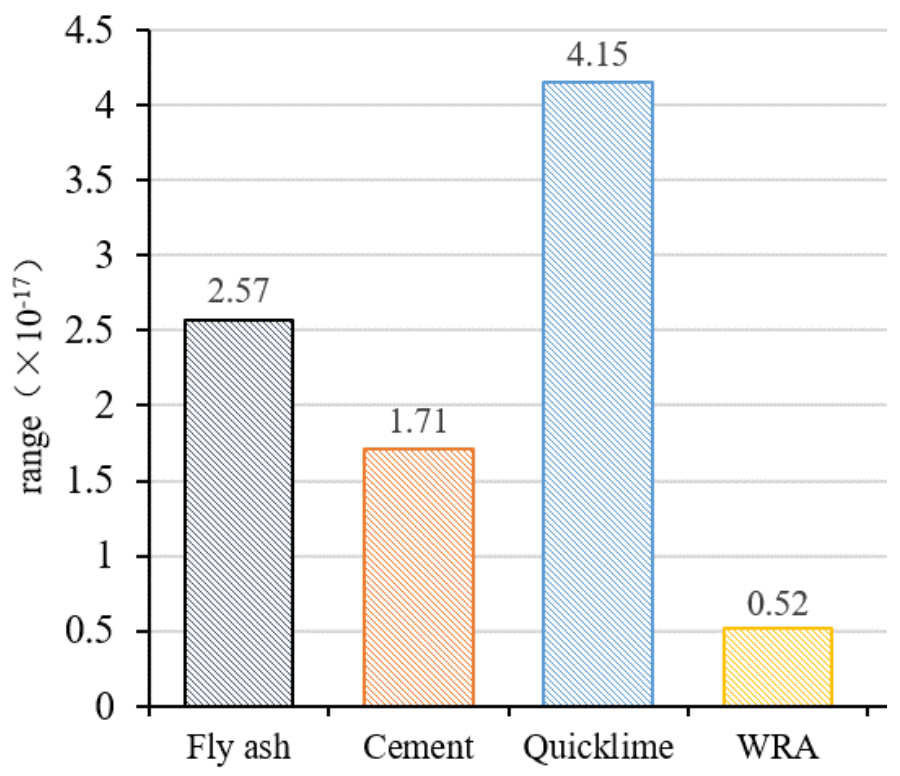

Fig. 8. Influence of the contents of different raw materials on SCB's permeability

As seen in Table 4 and Fig. 8, the decreasing order of $R_{\mathrm{m}}$ ranges was as follows: quicklime content $\left(R_{\mathrm{m}}=4.15\right)$, fly ash content $\left(R_{\mathrm{m}}=2.57\right)$, cement content $\left(R_{\mathrm{m}}=1.71\right)$, and WRA content $\left(R_{\mathrm{m}}=0.52\right)$. Thus, the quicklime content was the key influencing factor of SCB permeability, followed by fly ash, cement, and WRA contents. Thus, increasing the quicklime content was the most direct and effective way to decrease SCB's permeability. By contrast, changing the WRA content was the least effective.

\section{Conclusions}

(1) Permeability tests of SCB samples were performed, with the content of each main ingredient being varied one at a time. The results showed that quicklime and fly ash's contents had a greater impact on SCB's permeability than those of cement and water reducing agent (WRA). Under different contents of quicklime and fly ash, SCB's permeability ranged between $3.0 \times 10^{-2}$ and $7.15 \times 10^{-2} \mathrm{mD}$ and between $0.77 \times 10^{-2}$ and $3.34 \times 10^{-2} \mathrm{mD}$, respectively. Under different contents of cement and WRA, SCB's permeability varied between $2.3 \times 10^{-2}$ and $4.01 \times 10^{-2} \mathrm{mD}$ and between $2.88 \times 10^{-2}$ and $3.4 \times 10^{-2} \mathrm{mD}$, respectively.

(2) The Archimedes method, mercury intrusion porosimetry, and SEM scanning were employed to detect the porosity, pore size, and surface structure of the SCB samples, respectively. On this basis, the effect of different ingredients' contents on SCB's permeability was analyzed and theoretically substantiated. The SCB's permeability positively correlated with porosity, which ranged between 1.91 and $6.53 \%$ under different contents of the raw materials. The pore size 
392

positively correlated with permeability: the larger the pore size, the higher the permeability, and vice versa. The surface compactness indirectly reflected permeability changes. The greater the surface compactness, the lower the permeability; the lower the surface compactness, the higher the permeability.

(3) A range analysis was performed to analyze the sensitivity of SCB's permeability to the changes in different ingredients' contents. In descending order of the influence degree, the factors were ranked as follows: quicklime content $\left(R_{\mathrm{m}}=4.15\right)$; fly ash content $\left(R_{\mathrm{m}}=2.57\right)$; cement content $\left(R_{\mathrm{m}}=1.71\right)$; WRA content $\left(R_{\mathrm{m}}=0.52\right)$. Thus, the quicklime content was the most important influencing factor of permeability, followed by fly ash, cement, and WRA contents. Thus, increasing the quicklime content was the most direct and effective way to decrease SCB's permeability.

\section{Acknowledgements}

This work was supported by the National Natural Science Foundation [grant number 51874287], The authors would like to extend their thanks to the providers of the materials used in this study, and their appreciation to those who offered support for this study, including the Jinniu Coal Mine and CUMT.

\section{References}

[1] Zhang SQ et al. (1994) The influence of room temperature deformation on porosity and permeability in calcite aggregates. John Wiley \& Sons, Ltd. 99 (B8).

[2] Hamiel Y et al. (2005) Rock dilation, nonlinear deformation, and pore pressure change under shear. Earth Planet Sci Lett 237 (3):577-589. https://doi.org/10.1016/j.eps1.2005.06.028.

[3] Fall M et al. (2009) Saturated hydraulic conductivity of cemented paste backfill. Miner Eng 22 (15):13071317. https://doi.org/10.1016/j.mineng.2009.08.002.

[4] Abdul-Hussain N, Fall M (2011) Unsaturated hydraulic properties of cemented tailings backfill that contains sodium silicate. Eng Geol 123 (4):288-301. https://doi.org/10.1016/j.enggeo.2011.07.011.

[5] Zhang TS et al. (2011) A gap-graded particle size distribution for blended cements: Analytical approach and experimental validation. Powder Technol 214 (2):259-268. https://doi.org/10.1016/j.powtec.2011.08.018.

[6] Fridjonsson EO et al. (2013) Pore structure in a gold mine cemented paste backfill. Miner Eng 53:144151. https://doi.org/10.1016/j.mineng.2013.07.017.

[7] Ismail I et al. (2013) Influence of fly ash on the water and chloride permeability of alkali-activated slag mortars and concretes. Constr Build Mater 48:1187-1201. https://doi.org/10.1016/j.conbuildmat.2013.07.106. 

strength of cement paste. Powder Technol 234:19-25. https://doi.org/10.1016/j.powtec.2012.09.016.

[9] Mucsi G et al. (2013) Mechanical activation of cement in stirred media mill. Powder Technol 235:163172. https://doi.org/10.1016/j.powtec.2012.10.005.

[10] Liu J et al. (2014) Study on Surface Permeability of Concrete under Immersion. Mater 7 (2):876-886. https://doi.org/10.3390/ma7020876.

[11] Howladar MF and Karim MM (2015) The selection of backfill materials for Barapukuria underground coal mine, Dinajpur, Bangladesh: insight from the assessments of engineering properties of some selective materials. Environ Earth Sci 73 (10):6153-6165. https://doi.org/10.1007/s12665-014-3841-1.

[12] Fan L, Liu S (2017) A conceptual model to characterize and model compaction behavior and permeability evolution of broken rock mass in coal mine gobs. Int J Coal Geol 172:60-70. https://doi.org/ 10.1016/j.coal.2017. 01.017.

[13] Zhang BL et al. (2018) Nano-silica and silica fume modified cement mortar used as Surface Protection Material to enhance the impermeability. Cem Concr Compos 92:7-17. https://doi.org/10.1016/j.cemconcomp.2018. 05.012 .

[14] Zhang Y et al. (2018) Rheological properties and microstructure of fresh cement pastes with varied dispersion media and superplasticizers. Powder Technol 330:219-227. https://doi.org/10.1016/j.powtec.2018.02.014. [15] Panchal S et al. (2018) Mill tailings based composites as paste backfill in mines of U-bearing dolomitic limestone ore. J Rock Mech Geotech Eng 10 (02):310-322. https://doi.org/ 10.1016/j.jrmge.2017.08.004.

[16] Qureshi T et al. (2018) Autogenous self-healing of cement with expansive minerals-I: Impact in early age crack healing. Constr Build Mater 192:768-784. https://doi.org/ 10.1016/j.conbuildmat.2018.10.143.

[17] Behera SK et al. (2019) Strength development and microstructural investigation of lead-zinc mill tailings based paste backfill with fly ash as alternative binder. Cem Concr Compos 109. https://doi.org/ 10.1016/j.cemconcomp.2020.103553.

[18] Zhou N et al. (2019) Influential Factors in Transportation and Mechanical Properties of Aeolian SandBased Cemented Filling Material. Miner 9 (2). https://doi.org/ 10.3390/min9020116.

[19] Benyamina S et al. (2019) Performance of self-compacting concrete with manufactured crushed sand. Adv Concr Constr 7 (2):87-96. https://doi.org/10.12989/acc.2019.7.2.087.

[20] Alfonso I et al. (2019) Quantification of the microporosity effect on permeability of porous rocks. J Porous Media 23 (1):1-9. https://doi.org/ 10.1615/JPorMedia.2019028572.

[21] Sun Q et al. (2020) Experimental evaluation of physical, mechanical, and permeability parameters of key 
452 aquiclude strata in a typical mining area of China. J Cleaner Prod 267. https://doi.org/ 10.1016/j.jclepro.2020.122109.

453 [21] Chen SJ et al. (2020) Effects of red mud additions on gangue-cemented paste backfill properties. Powder 454 Technol 367:833-840. https://doi.org/ 10.1016/j.powtec.2020.03.055.

455 [23] Zhao HT et al. (2020) Investigation on sorptivity and capillarity coefficient of mortar and their relationship 456 based on microstructure. Constr Build Mater 265. https://doi.org/10.1016/j.conbuildmat.2020.120332.

457 [24] Zhou W et al. (2020) The mechanical and microstructural properties of refuse mudstone-GGBS-red mud 458 based geopolymer composites made with sand. Constr Build. Mater 253. https://doi.org/10.1016/j.conbuildmat.2020. 459119193.

460 [25] Chen JJ et al. (2020) Adding granite polishing waste as sand replacement to improve packing density, 461 rheology, strength and impermeability of mortar. Powder Technol 364:404-415. https://doi.org/10.1016/j.powtec.

$462 \quad 2020.02 .012$.

463 [26] Yan H et al. (2021) Crack propagation patterns and factors controlling complex crack network formation 464 in coal bodies during tri-axial supercritical carbon dioxide fracturing. Fuel 286:(P1). https://doi.org/10.1016/j.fuel. 4652020.119381

466 [27] Tibbetts CM et al. (2021) Improving the utility of MIP analysis for cementitious systems through Gaussian process regression modeling to predict electrical resistivity. Cem Concr Compos 116. https://doi.org/ 468 10.1016/j.cemconcomp.2020.103870.

469 [28] Bu YH et al. (2021) Low hydration exothermic well cement system: The application of energy storage 470 microspheres prepared by high-strength hollow microspheres carrying phase change materials. Cem Concr Compos 471 117. https://doi.org/10.1016/j.cemconcomp.2020.103907. 